\title{
VISUALIZING A FRAMEWORK FOR TANGIBILITY IN Multimedia Learning For Preschoolers
}

\author{
Chau Kien Tsong ${ }^{1}$, Toh Seong Chong ${ }^{2}$, Zarina Samsudin ${ }^{3}$, Wan Ahmad Jaafar \\ Wan Yahaya ${ }^{4}$, and ${ }^{5}$ Lili Budiman \\ ${ }^{1,2,3,4}$ Centre for Instructional Technology and Multimedia, Universiti Sains Malaysia, \\ 11800 USM, Pulau Pinang, Malaysia \\ ${ }^{1,5}$ School of Computing and IT \\ Taylor's University, No. 1 Jalan Taylor's, 47500 Subang Jaya, Selangor, Malaysia \\ ${ }^{1}$ kientsongeyahoo.com \\ ${ }^{2}$ tohsceusm.my \\ ${ }^{3}$ ina@usm.my \\ ${ }^{4}$ wajwy@usm.my \\ ${ }^{5}$ lili.budimandtaylors.edu.my
}

\begin{abstract}
This paper represents an attempt to conceive a tangible multimedia framework in educational settings. For preschoolers, the major drawback in conventional multimedia systems nowadays is the lack of concrete elements that allow them to learn naturally and tangibly. As Piaget stated that children aged below seven can only cognizant concrete objects (preoperational stage), there exists a large gap between preschoolers and digital multimedia. To bridge the gap, multimedia should and need to embrace tangible objects in learning. However, as a newly explored area, there is absence of discussion on how the tangible multimedia should look like. In response to this, a relevant framework that outlines the basic structure of such multimedia is visualized in this paper for reference as well as grounding guidelines. Relevant pilot study conducted revealed that tangible multimedia was efficacious in elevating preschoolers' learning performance, and motivation.
\end{abstract}

\section{KEYWORDS}

Tangible Multimedia, Preschoolers, Multimedia Learning, Tangible Object, Tangibility

\section{INTRODUCTION}

If we walk into any kindergarten in Malaysia, we will usually see a diverse collection of physical objects such as toys, scientific apparatus, manipulative blocks, and cartoon decoratives. In Malaysia, these objects serve many purposes, among them are to attract children, allow children to play during free period and create a harmonious environment for children. However, a great deal of these objects is seldom used in teaching and learning. Meanwhile, multimedia systems adopted as a means to deliver course contents has been an apparent trend [1][2][3]. In Malaysia, physical objects and multimedia are such two distinct entities, each serves its own purpose, one never used to complement each other, and never cross the border of another. This situation is very much different from overseas where they are already talking about how tangible objects can be utilized in ICT.

Tangible User Interface (TUI) was the first research area that initiated the idea of bringing tangible objects into computer systems. It has spurred many other similar research areas such as 
The International Journal of Multimedia \& Its Applications (IJMA) Vol.4, No.5, October 2012

augmented reality and mixed reality. Despite the rise of interest on such researches, multimedia researches in this direction are scarce [4]. In view of this, we propose a research on bringing tangible objects, which lead to tangibility sense into multimedia learning. We propose to term such multimedia system as "tangible multimedia learning system", or in short, tangible multimedia. Prior to full-scale experimental research [5], we visualize a framework that depicts the basic structure of tangibility in multimedia. It is the aim of this paper to discuss our rudimentary tangible multimedia framework in educational setting. Based on the framework, we developed a prototype named TangiLearn for pilot study. A brief report of the pilot study is provided at the end of this paper.

\section{WHY BRINGING TANGIBILITY INTO MULTIMEDIA LEARNING?}

For preschoolers, the major drawback in conventional multimedia learning systems nowadays are they lack the concrete elements that allow the children to learn naturally and tangibly. According to Piaget [6][7], children aged below 7 can only cognizant concrete objects because their cognitive structure is still at the preoperational stage. However, multimedia objects only presented in digital form, as such, there is a large learning gap between the preschoolers and multimedia learning system, a situation which could impede the children's learning.

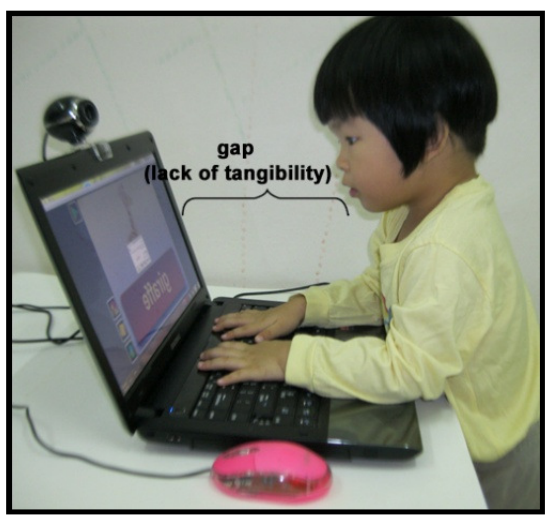

Figure 1. A gap between multimedia environment and preschoolers

Multimedia has been proven in playing role in children education [8][9]. There are also evidences supporting the fact that children learn about the world around them through tangible objects manipulation [10][11][12][13]. Elsom-Cook [14] said, "In going beyond a multimedia delivery system, our next level must be a system that permits physical interaction with the information channels" (p. 29). Under this circumstance, multimedia should and need to embrace tangible objects in multimedia learning to bridge the gap. However, as a newly explored area, we have problem to determine the structure of a tangible multimedia system. We are concern about the way the tangible objects should be used, the criteria to qualify a system as tangible multimedia, and the position of tangible objects in relation to multimedia objects. All these must be addressed because additional tangible objects add complexity to the system. If the structure of the tangible multimedia is not determined, the issue of physical clutter, display confusion, and the possibility of redundant usage of multimedia objects may be surfaced. In view of this, a relevant framework that outlines the basic structure of tangible multimedia is visualized in this paper as grounding guidelines and reference for researches of tangible multimedia in future.

\section{Framework For the Structure of TANGible MUltimedia}

The sole adoption of tangible objects in multimedia is not sufficient to constitute tangible multimedia. This situation is similar to the opinion of many researchers that the sole use of electronic devices in a learning scenario is not sufficient to constitute e-Learning [15]. 
The International Journal of Multimedia \& Its Applications (IJMA) Vol.4, No.5, October 2012

We adopt the use of the term "tangible" from Ullmer and Ishii's researches [16][17] in our proposed framework. Tangible object is physical object that has been augmented with computational power [18]. With multimedia objects physically embodied in a "tangible" form, humans can grasp and manipulate digital multimedia objects from the physical space [17]. On the contrary, "physical object" is a term given for physical objects that come without any augmentation of computational power. Original Froebel's gifts and Montessori materials are two good examples of physical objects.

Our proposed conceptual framework mainly defines the basic structure of "tangibility" in multimedia for preschoolers. We adopt Ullmer and Ishii [16]'s idea of TUI model as the base structure of tangible multimedia. In defining the overall structure of TUI model, Ullmer and Ishii put forth the GUI (Graphical User Interface) model for discussion. According to them, GUI model separates the information processing in computer into two different worlds, physical world and digital world (Figure 2). In the GUI model, mouse and keyboard (input devices) and computer monitor (output device) are two distinct entities in two different worlds. For a situation where a user types sentences on word processing software, the input is physical but the output is digital because it is displayed on computer screen. The gap between digital (hand for input) and physical (sight from computer screen) makes natural interaction difficult [17].

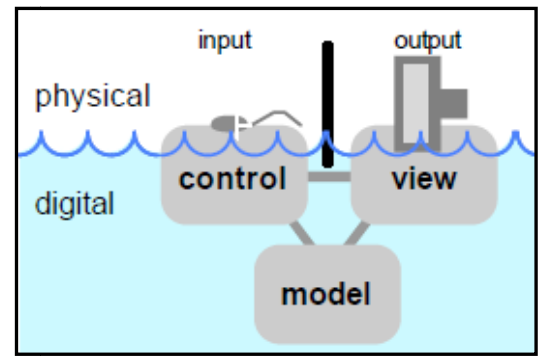

Figure 2. GUI model [16]

The emergence of TUI reshuffled the structure of the GUI model. Through the use of the tangible objects, digital information is shifted into physical world. Ullmer and Ishii [16] said this as "externalization of information into physical world" (Figure 3).

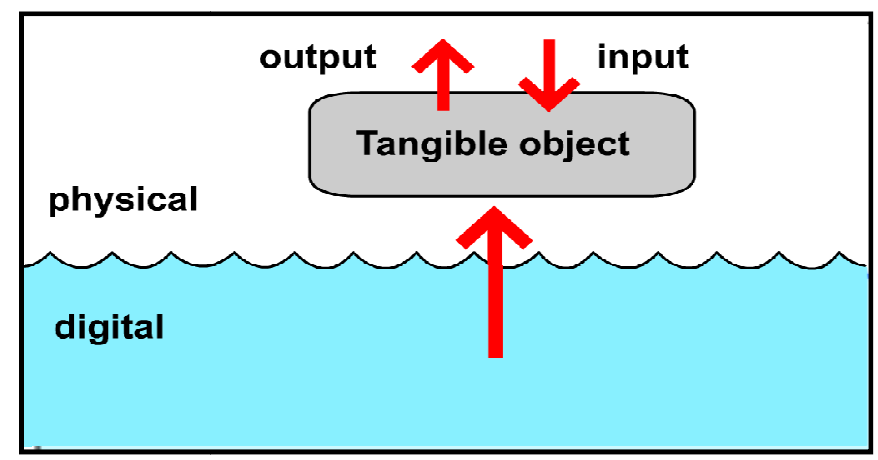

Figure 3. Externalization of information into physical world (adapted from [16])

This makes the distinction between input and output blurred. According to TUI model, to achieve a situation of seamless coupling of virtuality and tangibility, the most ideal situation is that input and output are no longer functioning as two distinct entities, but as one integrated unit. In other words, the input device should at the same time works as output device [16][19]. This idea is the opposite to the concept of virtual reality where analogue information is brought into virtual world, like in the movie entitled "Matrix". 
TUI model specifies tangible object as a means for realizing the externalization of information. The model adds, to truly constitute an object as tangible object, it must be both representational and controllable, as shown in Figure 4.

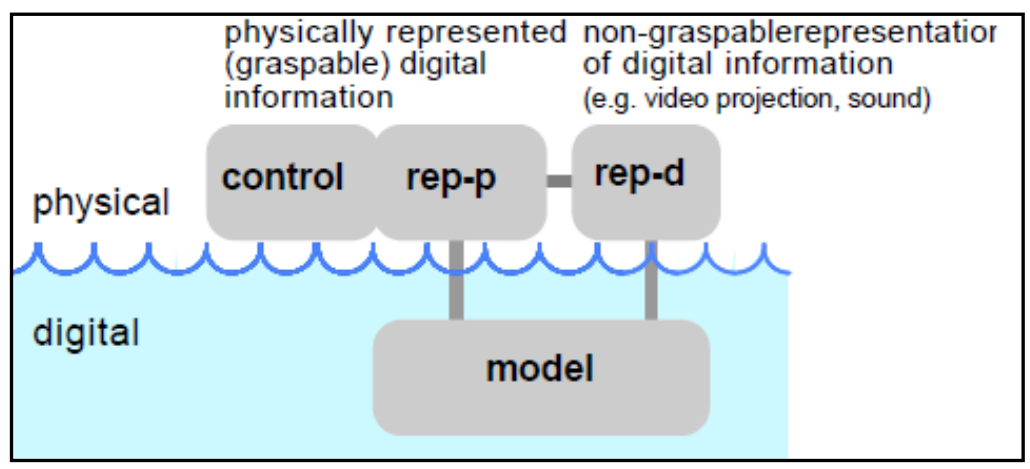

Figure 4. TUI model [16]

Mouse, keyboard and iPad (touch-screen) cannot be considered as tangible objects because they are not representational. They are incapable to be used to represent, or be in any form of metaphor for any digital information presented in computer system. They are merely used for controlling digital information, and thus can only be regarded as generic controllers. Compared to others, $i P a d$ serves as a more natural form of interface between human and computer.

Translated the idea of digital-physical concept model into multimedia realm, it is apparent that conventional multimedia nowadays are still in a state of GUI model, where all multimedia objects are functioning in digital world and only displayed through computer monitor (Figure 5). Even if touch-screen like iPad is adopted, the delivery of information is still done through digital world.

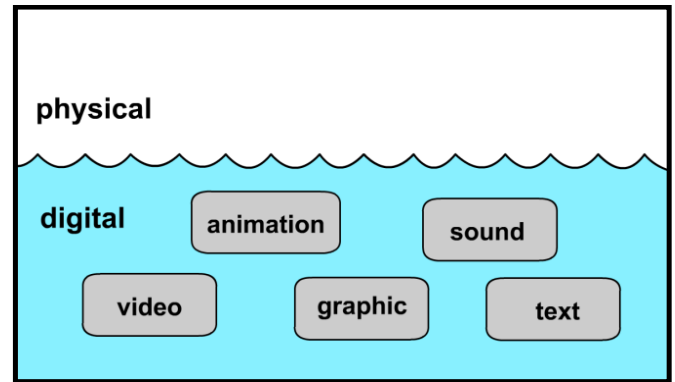

Figure 5. Multimedia objects in GUI model (adapted from [16])

To bridge the learning gap, a new paradigm shift in GUI-based multimedia systems for preschoolers has to be sorted out. We are of opinion that TUI model is a good choice of model because first, TUI systems are well researched for the past 16 years. Second, there are overwhelming supports for the use of tangible objects in preschoolers' learning from cognitivist and constructivist learning theories [36], Atkinson \& Shiffrin human memory theory [20], and Kieras \& Meyer's EPIC framework [21]. Reflecting the ideas of TUI model into multimedia learning, an ideal multimedia capable of bridging the gap of preschoolers and multimedia systems should resemble Figure 6. 
The International Journal of Multimedia \& Its Applications (IJMA) Vol.4, No.5, October 2012

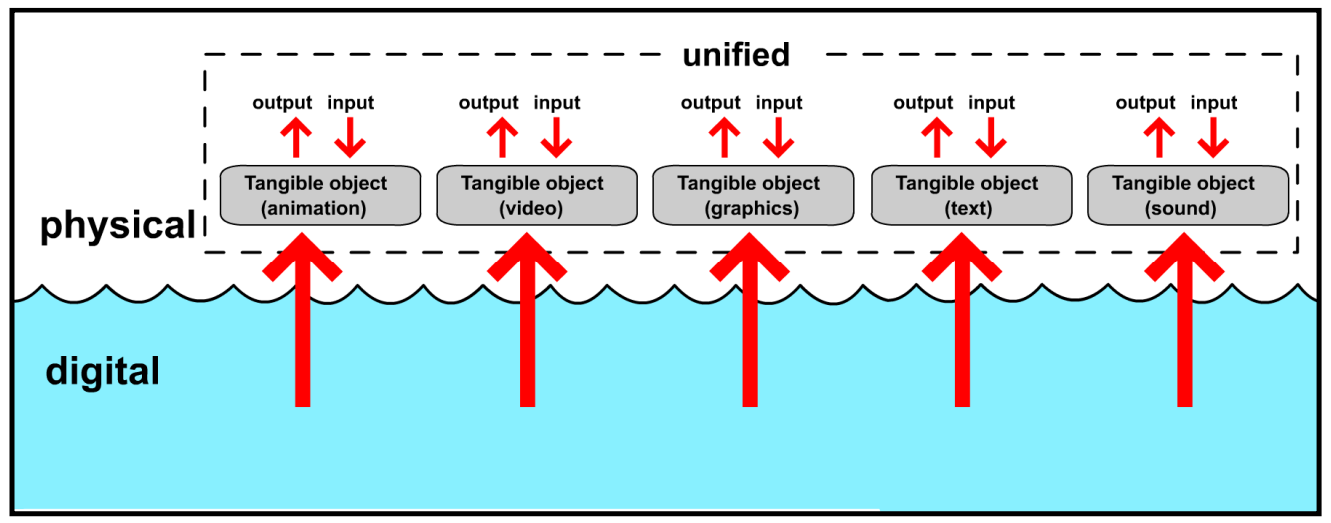

Figure 6. Externalization of multimedia objects in tangible multimedia

From the past TUI examples, we arguably conclude that all multimedia objects can be made tangible (externalized) using tangible objects. For graphics, real life objects such as pen, clock, cup, and fruits can be used directly to represent the virtual objects. For sound, it can be made "tangible", or more accurately, "real" by setting the sound generated from the objects itself after the users have applied certain forces on them (like TellTale in [22] and Jabberstamp in [23]. For animation and video, tangibility can be implemented by way of making the tangible objects to perform actual movement and corresponding multimedia effects in tandem (partly like Curlybot in [24]). Text can be made "tangible" by using paper, or cubes as a means to make the children feel text "tangible" (like Troll in [25] and Display Cube in [26]). For interactivity, real buttons can be placed on tangible objects (like VideoTable in [27] and PaperButtons in [28]).

A summary of scenario in Figure 6 is illustrated in Figure 7.

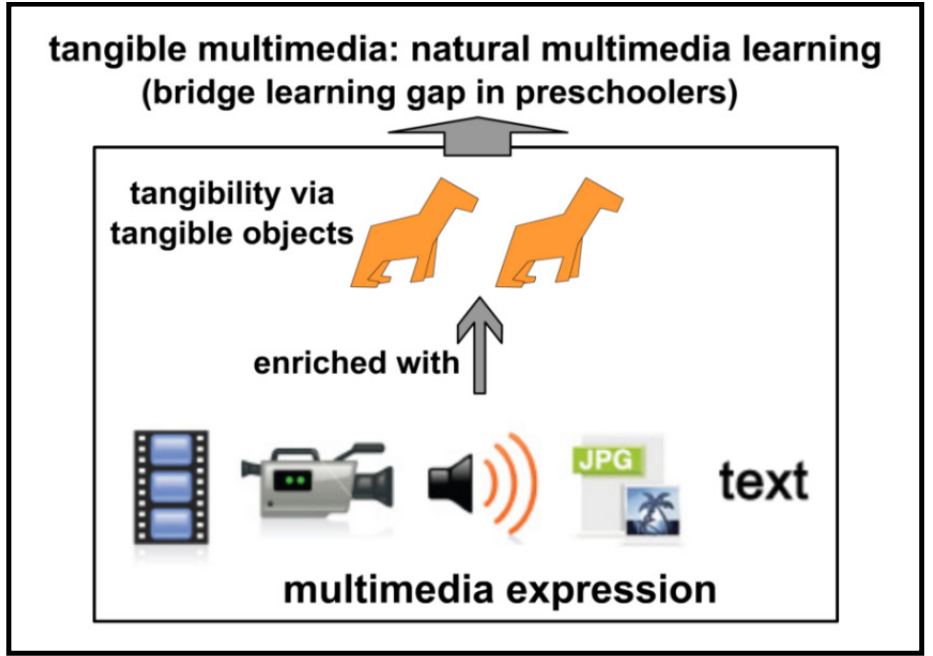

Figure 7. Bridging learning gap through tangible multimedia

Our proposed conceptual framework for tangible multimedia relies on TUI framework. Due to the nature of multimedia, we argue some conceptual differences with TUI framework. TUI merges the tangible objects and general digital information for interaction purposes [16][18]. For tangible multimedia, it merges the tangible objects and digital multimedia objects for the purpose of making the contents tangible so that they are cognitive-friendly to preschoolers. For example, tangible spoon is used to represent virtual spoon in an animated movie. Via such real-life objects, multimedia objects are "externalized" from digital world, and thereby gain their "tangibility". Besides, unlike TUI systems, tangible multimedia demonstrates significant use of multimedia 
The International Journal of Multimedia \& Its Applications (IJMA) Vol.4, No.5, October 2012

objects. To a great extent, we still need multimedia expression to make invisible abstract concepts or materials in "intangible" form (like water molecule, chemical reaction) visible. For TUI systems, they loosely relate tangible objects to multimedia objects, and deemphasize the role of multimedia design principles. Their interest is user interface surrounded on how tangible objects can be utilized as a new natural form of interface to facilitate better interaction with computer [29][30]. For them, multimedia objects are merely testing materials used for evaluating the usability of tangible objects as user interface. For this reason, TUI systems associated with multimedia are not rightfully tangible multimedia.

Tangible User Interface (TUI)

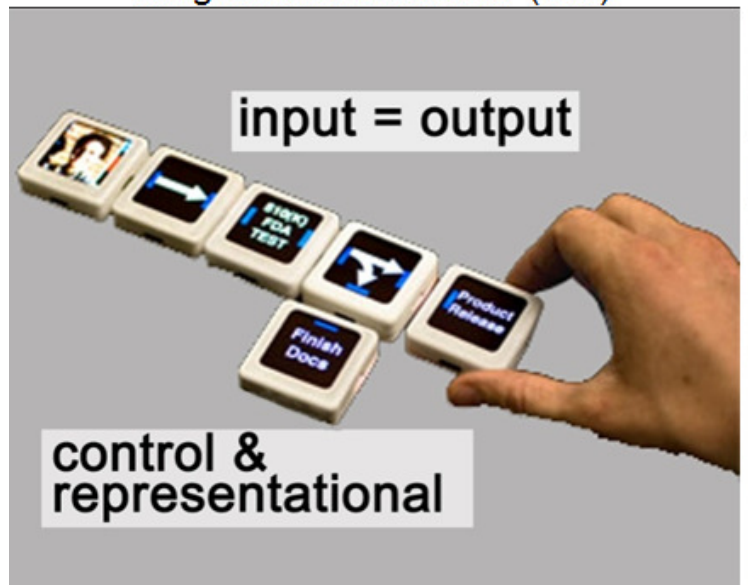

Tangible Multimedia

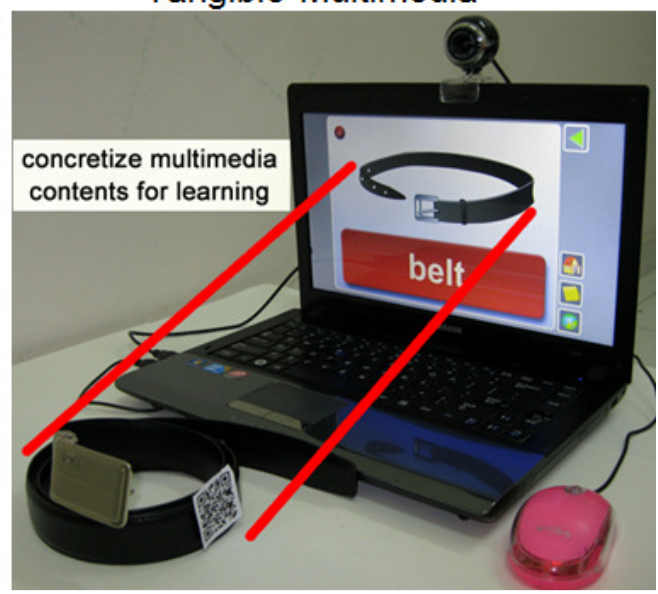

Figure 8. Difference between TUI and tangible multimedia

Tangible multimedia and TUI systems are also different in the extent of externalization of digital information. TUI systems aim to replace computer monitor, keyboard and mouse [31], as such, full externalization is their target. In the case of full externalization, all digital information, including multimedia objects are discarded. Examples of such TUI systems are Curlybot [24], SystemBlocks, Flowblock [32], and Topobo [33]. Full externalization of information should be avoided in tangible multimedia. We propose tangible multimedia should not seek to do away with any of the input or output devices, or downplay their value; otherwise, multimedia objects will have no position at all, and end up as animatronics machine. Furthermore, "full externalization" of information is impossible due to the fact that not all digital multimedia expressions, such as chemical reaction, can be made tangible. We still need input devices for accessing and controlling purposes. In this respect, we suggest a flexible approach in tangible multimedia. Mouse, keyboard, and computer screen will continue to play their role in tangible multimedia. To what extent the devices are used, or to what extent the multimedia objects are made tangible, would highly dependent on the requirements of the multimedia design principles [34], learning theories, the contents possible to be made tangible, or the need of the course. 
The International Journal of Multimedia \& Its Applications (IJMA) Vol.4, No.5, October 2012

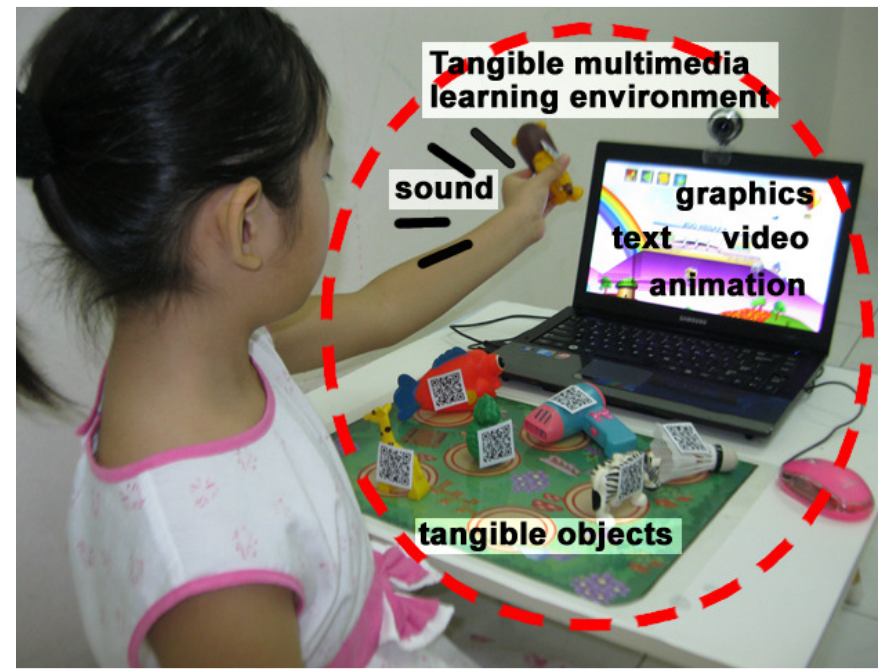

Figure 9. Significant use of multimedia objects in tangible multimedia

Extended from the point where tangible objects are no longer merely designated as interaction interface, more differences from TUI systems in terms of the ways the tangible objects used can be conceived in tangible multimedia. As tangible objects are freed up from its functionality as input devices, physical control, and representational tool, or as digital manipulative which are commonly studied in TUI, tangible objects can be used in more variety of ways. They can be now used as live learning objects, as explanatory objects to deliver content and concepts, as live resources tool to provide extra information, as an educative toy, as a way to attract learner, as a way to track the multimedia objects, as additional aid that supplement multimedia objects, as reminder for children for something, as scaffolding tools, as link to more other different tangible objects in physical world, as figurines and decorative objects to capture the children's attention, as demonstrated exemplars capable of providing certain information for learning (e.g., when a child throws the ball in the air, the ball's velocity and acceleration are measured and plotted on screen using various multimedia ways), or as avatar (either tangible objects are turned into avatars to represent the players, or the users themselves turned into tangible objects. For example, the users may directly carry the RFID tags, and make themselves the objects of their own interactions, and access the information embedded in objects from surrounding).

In tangible multimedia, we also propose that tangible objects should not be categorized under the category of visual channel. This point is raised here because many researchers adopt the belief that tactile, gustatory, and olfactory stimuli are logged through the visual channels [35], as in most of the influential multimedia design theories such as Mayer's cognitive theory of multimedia learning, cognitive load theory and dual coding theory, which only discuss two sensory channels of information receiving. There might be limitations in these theories and we suggest more researches to look into this. Our argument points are first, tangible objects provide spatial and tactile information which is very much different from visual information in nature. Second, through touch and feel, a blind or mute person can identify an object. Third, there are two compelling human memory theories, Atkinson \& Shiffrin [20] human memory theory and Kieras \& Meyer's EPIC framework [21] postulate the role of tactile sensory channel in registering tactile information from the outside world [36]. These theories assert that information input to human memory system is not solely dependent on visual and auditory channel. Forth, if animations and videos are treated differently, tangible objects should also receive similar treatment. In many aspects, graphics, animation, and video are similar. They are all visually engaging and stimulate the same sense. Animation and video are made of graphics, with just additional attribute in time. However, they are still separated as three distinct multimedia objects. Under this circumstance, it is logical, and makes sense to set tangible objects as another category of multimedia object. Based 
The International Journal of Multimedia \& Its Applications (IJMA) Vol.4, No.5, October 2012

on the above arguments, we propose tangible object to be regarded as a category of multimedia objects on its own. With this, taxonomy of tangible multimedia is to be defined as the combination of six multimedia objects, namely graphic, animation, text, audio, video and tangible objects.

In the case where tangible objects are now one of the multimedia objects, tangible multimedia as such should be researched as a whole, not tangible object alone. In other words, evaluating tangible multimedia means evaluating the system as a single coherent whole. All the multimedia objects are taken together seamlessly, and each multimedia object, including tangible object, is considered only in relation to the whole. One of the characteristics of multimedia is that multimedia objects are delivered to users as a well integrated entity through single computer monitor [37]. Compliant with this characteristic, all multimedia objects in tangible multimedia should be designed to be equally important, and unified (Figure 6) in a way that they complement each other meaningfully to achieve the overall tangibility experience that eventually lead to efficient learning. In the era of media convergence, the entirety of children's experiences in media environment should be considered rather than discrete elements of it [38]. If tangible objects are isolated from the whole system and investigated individually, it will turn out to be a TUI research. Xie [39], Antle, Droumeva, and Ha [11] and Xu [40] had conducted researches on the efficacy of tangible objects alone, and repetition of such research should be avoided. Undertake

\section{Pilot STUdy}

Based on the tangible multimedia framework visualized above, a low-fidelity prototype of tangible multimedia, TangiLearn was developed. To ensure the quality of the system developed, a series of formal evaluation strategies was employed for evaluating the working prototype prior to the actual experimental research. An on-going process of iterative cycle of drafting, evaluation and revision will be conducted until the final TangiLearn works.

This section serves as a report of what we observed during the first pilot study, one-to-one individual trial. We look for preliminary evidence to support the assumption that TangiLearn can enhance children's motivation and learning performance [41]. The one-day study was conducted on one-to-one basis with six preschoolers aged 6 from a kindergarten in Kuala Lumpur who were representative of the targeted subjects. Unstructured observation, interviewing and questionnaires (pre-quiz, post-quiz, and PMMS [50]) were employed.

All participants were required to sit for a pre-quiz three days before the experiment. When the study commenced, the participants were asked to explore TangiLearn freely for 30 minutes. There were 16 tangible objects displayed in front of computer. If the participants grasped a tangible lion and showed to the computer camera, the virtual lion would display corresponding animations and videos about the lions on the computer screen. Upon completion of learning session, the participants would need to answer the post-quiz by identifying and picking up the correct tangible object. Learning object refers to the unit of knowledge intended to be delivered to the participants. The participants are expected to understand these learning objects, and master relevant key terms learnt from the system. 
The International Journal of Multimedia \& Its Applications (IJMA) Vol.4, No.5, October 2012

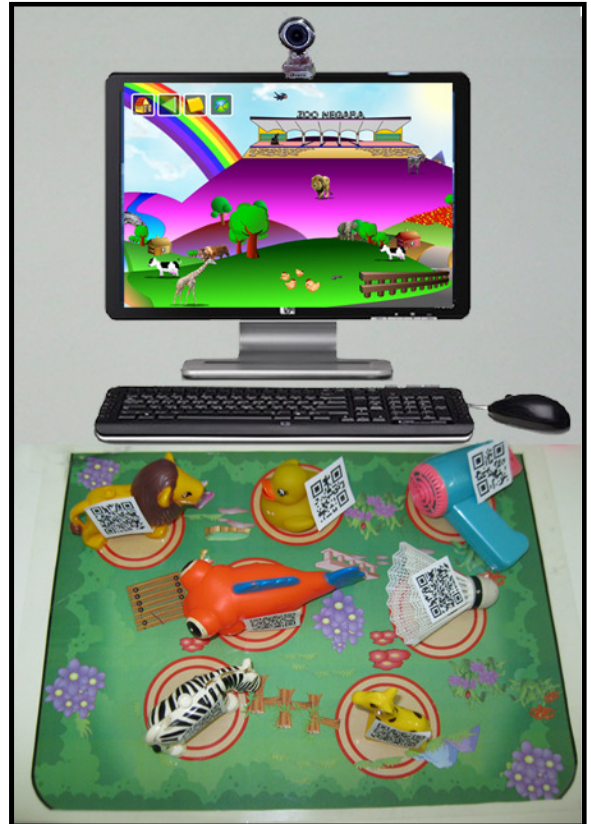

Figure 10. Tangible and virtual learning objects in TangiLearn

We used an open source visual machine readable marker technology called Quick Response (QR) code integrated with Flash library to bind the tangible and multimedia objects (Figure 11). Considering its technologically simple, affordability, and adaptability to low capacity of computer, the QR code is considered a good choice for such binding [48].
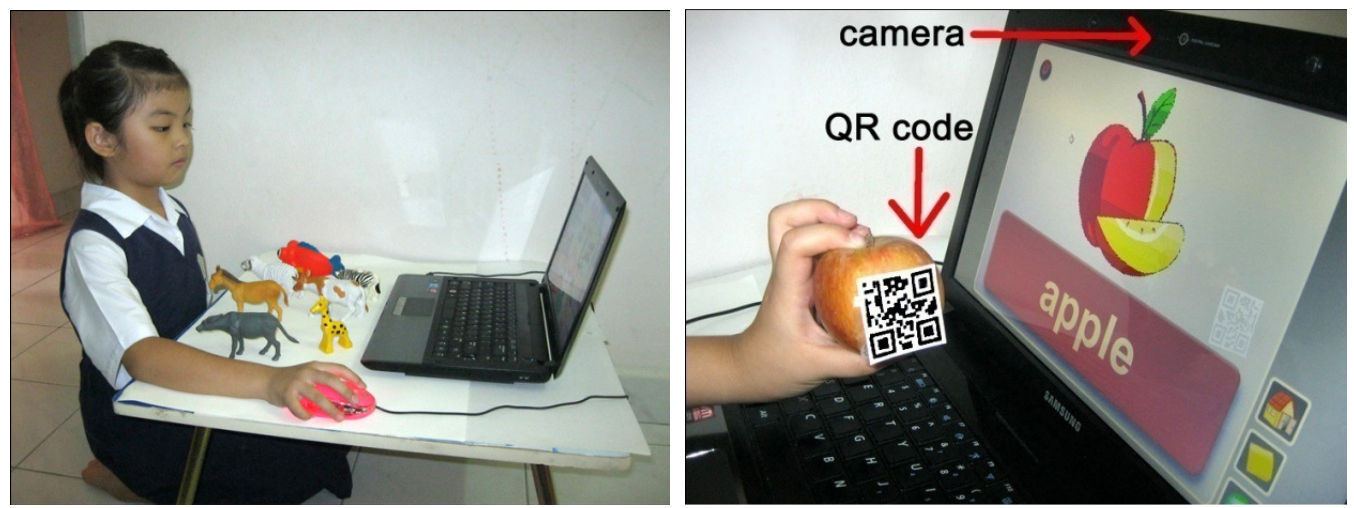

Figure 11. TangiLearn set up using QR code marker

QR code visual marker is designed in a unique 2D symbol code graphical matrix form in black and white colour. It is similar to implementation using image processing method in a way that they both use computer vision algorithm to process and recognise the object via image and video captured by computer camera. The difference is, instead of directly detecting the tangible object, the algorithm detects the visual marker attached on the tangible object. In other words, the visual marker gives a visually identifiable identity to the object. Although direct object recognition using image processing method is feasible for tangible multimedia development (successful examples of TUI systems using image processing methods were DigitalDesk [44][45], video puppetry system [46], and TANGerINE system [47]), unique condition in TangiLearn does not seem to consider the method as a viable option. For TangiLearn [5], 16 tangible objects will be utilised as learning objects. As image processing method requires all tangible objects to be distinct enough for accurate recognition, thus a series of customized algorithms for each of the 
different objects will be required. As a result, the image processing algorithm requires not only extensive programming skills, but also sophisticated algorithm which is always far beyond the capability of a developer from the multimedia background. Besides, for a system like TangiLearn that needs to be used in kindergarten, versatility in different lighting condition is another great concern. In Malaysia, it is common that a bungalow or a corner side double storey terrace is used as kindergarten. In this situation, computer rooms may be arbitrarily set. Some may simply use a room at the back of the bungalow, or simply somewhere near to the kitchen as computer lab. As condition of lighting is such varied in kindergartens, recognition using image processing method could be a problem. With QR code library, the demand for excessive programming is greatly "scaled-down". The designers from the multimedia background are thus able to leave out the challenging programming in binding processing logic, and concentrate on the core functionality of the tangible multimedia. On the same note, QR code is more versatile in various lighting conditions. One example of successful use of QR code in TUI systems was Icandy [43].

Unstructured interview and observation discovered that the participants liked holding the tangible objects. Their emotional and facial expression revealed that TangiLearn was a novel system to them because they have not seen any computer system coupled with tangible objects before, as such, they liked most the part where tangible objects were bound up with multimedia expressions. They seemed to be deceived into the belief that the digital multimedia objects had been made "graspable" in physical space.

Quantitative results had helped support the qualitative results that TangiLearn was an educationally valuable system. The total score of quizzes (Figure 12) is used as a measure of the knowledge of participants on contents acquired in the pilot study. Similar to learning session, the participants would need to answer the questions by picking up the correct tangible object. There were 15 questions in both pre and post-quiz. 1 mark was awarded for correct answer and 0 for incorrect answer (Full marks = 15 marks). Pre-quiz and post-quiz were similar in some contents, but were arranged in a randomised order to avoid the "set response effect" or any possible interactions between them.

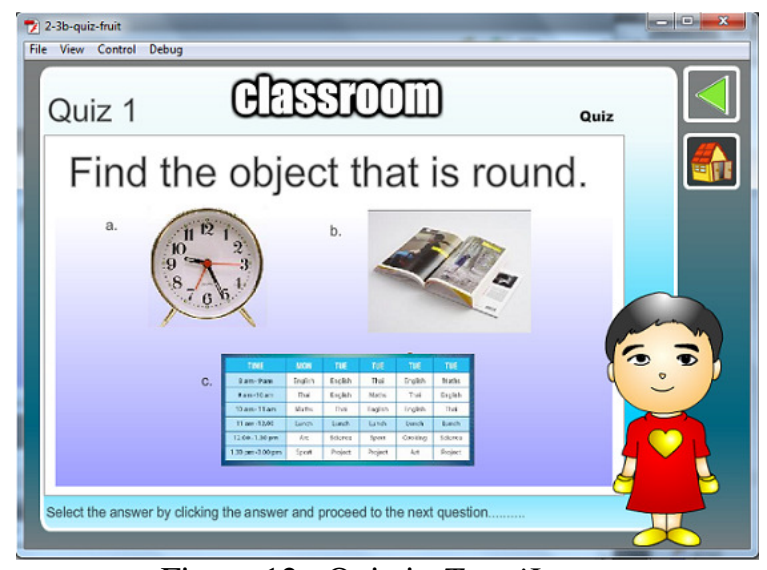

Figure 12. Quiz in TangiLearn

As there were only a few participants in the pilot study, we administered the study ourselves, and used basic descriptive statistics for analysis. The full comparative experimental research covering 250 students is being planned [5].

Table 1. Scores of the Pre-quiz \& Post-quiz 
The International Journal of Multimedia \& Its Applications (IJMA) Vol.4, No.5, October 2012

\begin{tabular}{|c|c|c|c|}
\hline $\begin{array}{c}\text { Type of } \\
\text { quiz }\end{array}$ & $\mathrm{N}$ & Mean & $\begin{array}{c}\text { Std. } \\
\text { Deviation }\end{array}$ \\
\hline Pre-quiz & \multirow{2}{*}{6} & 6.83 & 0.75 \\
\hline Post-quiz & & 11.83 & 0.98 \\
\hline
\end{tabular}

Table 1 reveals that Mean scores were generally low in pre-quiz. After treatment, the participants showed significant improvement in post-quiz. A higher conceptual understanding Mean score in post-quiz demonstrated that participants successfully learned from the system.

PMMS (Persuasive Multimedia Motivation Scale) instrument created by Sobihatun [50] was used to gauge the participants' level of motivation after treatment using TangiLearn. PMMS is initially used for persuasive multimedia learning environment [50]. It was adapted from Keller's IMMS (Instructional Materials Motivation Scale) [51] in Malay language version, translated by Toh [52], with cronchbach's alpha reliability coefficient of 0.81. Keller's IMMS is an instrument meant for adult. As the target subjects of this study were preschoolers of 5 and 6 years old, so an instrument specially catered for their level has to be deployed. Because of this, PMMS was employed in this study. We slightly modified the PMMS to suit to the context of TangiLearn and an example of PMMS is shown as follows.

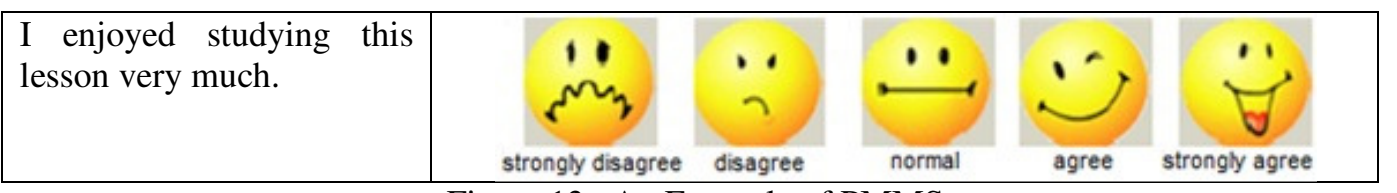

Figure 13. An Example of PMMS

The PMMS consisted of ten items. Participants were required to respond to both positively and negatively worded statements by marking their opinions on a set of five faces representing a scale of 1 (strongly disagree), 2 (disagree), 3 (neither agree nor disagree), 4 (agree) and 5 (strongly agree). There were no correct or wrong answers.

Table 2. Results of the PMMS scores on using TangiLearn

\begin{tabular}{|l|l|c|c|}
\hline \multicolumn{1}{|c|}{ Evaluation Items } & Average & \multicolumn{1}{|c|}{$\begin{array}{c}\text { Motivation } \\
\text { Level }\end{array}$} \\
\hline 1 & I understand this lesson easily. & 4 & effective \\
\hline 2 & I like the tangible objects in this lesson. & 5 & Most effective \\
\hline 3 & I knew what I was supposed to learn from this lesson. & 5 & Most effective \\
\hline 4 & These materials are eye-catching. & 5 & Most effective \\
\hline 5 & I enjoyed the information is presented in this lesson. & 4 & effective \\
\hline 6 & I am more interested in this lesson. & 5 & Most effective \\
\hline 7 & I enjoyed studying this lesson very much. & 5 & Most effective \\
\hline 8 & This system helped me to not worry about the exam. & 5 & Most effective \\
\hline 9 & I like to see a lot of cartoons on a computer. & 4 & effective \\
\hline 10 & It was a pleasure to work on this lesson. & 5 & Most effective \\
\hline
\end{tabular}

We believed the use of tangible objects greatly contributed to the positive learning outcome. Through the system, they had the opportunity to tinker with the tangible objects, and performed trial and error manipulation in front of the computer. Overall, the outcome of this pilot study was positive and encouraging.

Another important finding we discovered was that the use of direct representation of tangible objects to the digital multimedia objects was as good as symbolic mapping in enhancing learning. 
The International Journal of Multimedia \& Its Applications (IJMA) Vol.4, No.5, October 2012

In TUI researches, many of the features of manipulative materials (e.g. cubes, rods) are scrapped, simplified, and used to represent other domains, such as shapes for coins and different colours for numbers. They argued that this is the correct way of using tangible objects; otherwise, their effectiveness will be degraded [42]. In our pilot study, we did not follow the TUI researches; instead, we design the tangible objects to represent themselves in the virtual world in TangiLearn.

\section{CONCLUSION}

In this paper, we attempt to outline the way a tangible multimedia should look like by proposing a rudimentary framework. However, there exist several challenges if we are to implement the proposed framework for tangible multimedia. This is because first, the scope of multimedia is very wide and diversified, ranging from casual games to highly realistic 3D virtual reality applications. Second, thus far there is not one best technology capable for its implementation. Although there have been various TUI system toolkits available for development nowadays, their deployment is still imperfect and imposes certain difficulties. For example, the deployment of visual marker technology, as in our pilot study, observes occasional difficulties in detection execution. For sensing technology such as RFID and sensor devices, wired connection gives restriction of freedom for movement. Other than that, not all multimedia expressions, such as chemical reaction and molecular flow, can be made tangible.

Despite the challenges and problems, the framework for tangible multimedia is still conceptually strong and theoretically riveting. Preliminary evidence gathered in the pilot study has further demonstrated the feasibility of such system in learning empirically. As a newly explored area, discussion on the formation of the framework is required for assessment of the correct use of tangible objects within multimedia context as well as grounding guidelines and reference for research on tangibility in multimedia landscape in future. If tangible objects in multimedia are used subjectively and arbitrarily, intended purpose of tangible multimedia may be counterproductive. We wish there will be more empirical study on such framework for tangible multimedia. Future researches may also focus on the application of the framework in preschoolers' education, or the correctness, accuracy and feasibility of the framework in real situation.

\section{REFERENCES}

[1] Zarina Che Embi \& Hanafizan Hussain. (2003) "Empirical Study on Implementation of a Framework for Edutainment Environment", Proceedings of International Conference on New Educational Environments. ICNEE 5th. Lucerne, Switzerland.

[2] Zarina Che Embi \& Hanafizan Hussain. (2005) "Analysis of local and foreign edutainment products: An effort to implement the design framework for an edutainment environment in Malaysia", Journal of Computers in Mathematics and Science Teaching, 24(1), pp27-42. Norfolk, VA, AACE. Retrieved from http://www.thefreelibrary.com/Analysis+of+local+and+foreign+edutainment+products-an+effort+to...-a0128170452

[3] Cut Nora Azizah. (2010) Potentials of interactive digital storytelling for preschool children in daily reading activity, Unpublished Master Dissertation, Universiti Utara Malaysia.

[4] Chau K. T., Toh S. C., \& Zarina Samsudin. (2012) "Bringing Tangibility into Multimedia Learning: From the Past TUI Researches to Tangible Multimedia for Preschool Children", Proceedings of the International Conference on E-Education \& Learning Technologies (ICEELT 2012), August 13- 14, 2012, Singapore.

[5] Chau, K. T., Toh, S. C., \& Zarina Samsudin. (2011) "Tangible multimedia technology: A research proposal for bringing tangibility into multimedia learning amongst preschool children", Proceedings of the 5th International Malaysian Educational Technology Convention (IMETC 2011), Kuantan, Malaysia, October 16-19, 2011. 
The International Journal of Multimedia \& Its Applications (IJMA) Vol.4, No.5, October 2012

[6] Piaget, J. (1952) The origins of intelligence in children, New York, USA, University Press.

[7] Piaget, J. (1972) The principles of genetic epistemology, New York, Basic Books.

[8] Kulik, J., Kulik, C., \& Cohen, P. (1980) "Effectiveness of computer-based college teaching: A meta analysis of findings", Review of Educational Research, 50, pp525-544.

[9] Williamson V. M., \& Abraham, M. R. (1995) "The effects of computer animation on particulate mental models of college chemistry students", Journal of Research in Science Teaching, 32(5), pp521-534.

[10] Khandelwal, M., \& Mazalek, A. (2007) "Teaching Table: A tangible mentor for pre-K math education", Proceedings from TEI '07: The 1st International Conference on Tangible and Embedded Interaction, pp191-194.

[11] Antle, A. N., Droumeva, M., \& Ha, D. (2009) "Hands on what? Comparing children's mouse-based and tangible-based Interaction", Proceedings from IDC '09: The 8th International Conference on Interaction Design and Children, pp80-88.

[12] Xie, Z. (2008) Comparing children's enjoyment and engagement using physical, graphical and tangible user interfaces, Master dissertation, School of Interactive Arts and Technology, Simon Fraser University, Canada.

[13] Chau, K. T., Toh, S. C., \& Zarina Samsudin. (2012) "Enriching multimedia expression with tangible objects: the learning benefits for preschoolers", Procedia - Social and Behavioral Sciences, Elsevier. (in press)

[14] Elsom-Cook, M. (2001) Principles of Interactive Multimedia, United Kingdom, McGraw-Hill.

[15] Tavangarian, D., Leypold, M. E., Nölting, K., Röser, M., \& Voigt, D. (2004) "Is e-Learning the Solution for Individual Learning?", Electronic Journal of e-Learning, 2(2), pp273-280.

[16] Ullmer, B., \& Ishii, H. (2001) “Emerging Frameworks for Tangible User Interfaces”. In Carroll, J. M. (ed.), Human-Computer Interaction in the New Millenium, pp579-601, USA, Addison-Wesley.

[17] Ishii, H., \& Ullmer, B. (1997) "Tangible bits: Towards seamless interfaces between people, bits, and atoms", Proceedings of the ACM SIGCHI Conference on Human Factors in Computing Systems, pp234-241.

[18] Manches, A. (2010) The effect of physical manipulation on children's numerical strategies: Evaluating the potential for tangible technology, Unpublished doctoral dissertation, University of Nottingham, United Kingdom.

[19] Jetsu I. (2008) Tangible User Interfaces and Programming, Master Dissertation, Department of Computer Science and Statistics, University of Joensuu, Finland.

[20] Atkinson, R. L., \& Shiffrin, R. M. (1968) "Human memory: A proposed system and its control processes". In K. W. Spence \& J. T. Spence (Eds.) The psychology of learning and motivation: Advances in research and theory, 2, pp89-195. New York, Academic.

[21] Kieras, D. E., \& Meyer, D. E. (1997) "An overview of the EPIC architecture for cognition and performance with application to human-computer interaction", Human-Computer Interaction, 12, pp391-438. Lawrence Erlbaum Associates.

[22] Ananny, M. (2002) "Supporting children's collaborative authoring: Practicing written literacy while composing oral texts", Proceedings of Computer Support for Collaborative Learning, pp595-596, New Jersey, USA, Lawrence Erlbaum Associates.

[23] Raffle, H., Vaucelle, C., Wang, R., \& Ishii, H. (2007) "Jabberstamp: embedding sound and voice in traditional drawings", Proceedings from IDC '07: The 6th International Conference on Interaction Design and Children, pp137-144.

[24] Frei, P., Su, V., Mikhak, B., \& Ishii, H. (2000) "Curlybot: Designing a new class of computational toys", Proceedings of the SIGCHI Conference on Human Factors in Computing Systems, 129-136. 
The International Journal of Multimedia \& Its Applications (IJMA) Vol.4, No.5, October 2012

[25] Soro, A., Deriu, M., \& Paddeu, G. (2009) "Natural exploration of multimedia contents", Proceedings of MoMM2009: The 7th International Conference on Advances in Mobile Computing and Multimedia, pp382-385.

[26] Kranz, M., Schmidt, D., Holleis, P., \& Schmidt, A. (2005) “A display cube as a tangible user interface", Proceedings of the Seventh Internation Conference on Ubiquitous Computing, Switzerland, Springer.

[27] Sokoler, T., Edeholt, H., \& Johansson, M. (2002) "VideoTable: A tangible interface for collaborative exploration of video material during design sessions", Proceedings from CHI 2002, pp656-657.

[28] Pedersen, E. R., Sokoler, T., \& Nelson, L. (2000) "PaperButtons: Expanding a tangible interface", Proceedings from DIS '00: The 3rd Conference on Designing Interactive Systems: Processes, Practices, Methods, and Techniques, pp216-223.

[29] Dourish, P. (2001) Where the Action Is: The Foundations of Embodied Interaction, USA, MIT Press.

[30] Marshall, P., Price, S., \& Rogers, Y. (2003) "Conceptualising tangibles to support learning”. Interaction Design and Children, pp101-109.

[31] Marco, J., Cerezo, E., Baldassarri, S., Mazzone, E., \& Read, J. C. (2009) "Bringing tabletop technologies to kindergarten children", Proceedings from BCS-HCI '09: The 23rd British HCI Group Annual Conference on People and Computers: Celebrating People and Technology, pp103-111.

[32] Zuckerman, O., Arida, S., \& Resnick, M. (2005) "Extending tangible interfaces for education: Digital Montessori-inspired manipulatives", Proceedings of the ACM SIGCHI conference on Human factors in computing systems, pp859-868.

[33] Raffle, H., Parkes, A., \& Ishii, H. (2004) "Topobo: A constructive assembly system with kinetic memory", Proceedings of the SIGCHI Conference on Human Factors in Computing Systems, pp647654.

[34] Chau, K. T., Toh, S. C., \& Zarina Samsudin. (2012) "Designing tangible multimedia for preschool children based on multimedia design theories", International Journal of Scientific \& Engineering Research (3)8. (in press)

[35] Metiri Group. (2008) Multimodal learning through media: What the research says, Cisco White Paper, USA, Cisco Public Information. Retrieved from http://www.cisco.com/web/strategy/docs/education/Multimodal-Learning-Through-Media.pdf

[36] Chau K. T., Toh S. C., Zarina Samsudin, \& Wan Ahmad Jaafar Wan Yahaya. (2012) "Tangible Objects: The Missing Attribute in Multimedia Learning Systems for Preschoolers", The International Journal of Multimedia \& Its Applications (IJMA). (under review)

[37] Nahrstedt, K., \& Steinmetz, R. (2002) Multimedia fundamentals volume 1: media coding and content processing, US, Prentice Hall.

[38] Plowman, L., \& Stephen, C. (2003) “A 'benign addition'? Research on ICT and pre-school children”, Journal of Computer Assisted Learning, 19, pp149-164.

[39] Xie, Z. (2008) Comparing children's enjoyment and engagement using physical, graphical and tangible user interfaces, Master dissertation, School of Interactive Arts and Technology, Simon Fraser University, Canada.

[40] Xu, D. (2005) Tangible user interface for children: An overview [Technical report], University of Central Lancashire, Preston, United Kingdom.

[41] Chau, K. T., Toh, S. C., \& Zarina Samsudin. (2012b) "Tangible multimedia: A case study for bringing tangibility into multimedia learning", Procedia - Social and Behavioral Sciences, Elsevier. (in press)

[42] O’Malley, C., \& Fraser D. S. (2004) Futurelab Series Report 12: Literature review in learning with tangible technologies, Bristol, United Kingdom, NESTA Futurelab. Retrieved from http://www.futurelab.org.uk/download/pdfs/research/lit_reviews/ futurelab_review_12.pdf 
The International Journal of Multimedia \& Its Applications (IJMA) Vol.4, No.5, October 2012

[43] Graham, J., \& Hull, J. J. (2008) "Icandy: A tangible user interface for itunes", Proceedings from CHI EA '08: The Extended Abstracts on Human Factors in Computing Systems, pp2343-2348.

[44] Wellner, P. D. (1993) "Interacting with paper on the DigitalDesk", Communications of the ACM: Special issue on computer augmented environments: back to the real world, 36(7), pp87-96.

[45] Wellner, P. D. (1994) Interacting with paper on the DigitalDesk [Technical Report No. 330]. UK: University of Cambridge Computer Laboratory.

[46] Barnes, C., Jacobs, D. E., Sanders, J., Goldman, D. B., Rusinkiewicz, S., Finkelstein, A., \& Agrawala, M. (2008) "Video puppetry: A performative interface for cutout animation", SIGGRAPH Asia '08: ACM Transactions on Graphics, 27(5), pp124:1 - 124:9.

[47] Baraldi, S., Bimbo, A. D., Landucci, L., Torpei, N., Cafini, O., Farella, E., Pieracci, A., \& Benini, L. (2007) "Introducing tangerine: A tangible interactive natural environment", Proceedings from MM '07: The 15th International Conference on Multimedia, pp831-834.

[48] Chau K. T., Toh S. C., Zarina Samsudin, \& Wan Ahmad Jaafar Wan Yahaya. (2012), "Bringing Tangibility into Multimedia Learning: Technology for Tangible-Multimedia Objects Binding", Proceedings of the International Conference on Quality Of Teaching \& Learning (ICQTL 2012), October 23-24, Malaysia. (in press)

[49] Read, J. C., MacFarlane, S. J. \& Casey, C. (2002) "Endurability, Engagement and Expectations: Measuring Children's Fun”, Proceedings from IDC'02. ACM Press.

[50] Sobihatun Nur Bt Abdul Salam. (2010). The development and effects of a persuasive multimedia learning environment (PMLE) in reducing children dental anxiety. Unpublished doctoral dissertation. Universiti Sains Malaysia, Penang.

[51] Keller, J. M. (2010). Motivational Design for Learning and Performance: The ARCS Model Approach. USA: Springer.

[52] Toh, S.C. (1998). Cognitive and motivational effects of two multimedia simulation presentation modes on science learning. Unpublished doctoral dissertation, Universiti Sains Malaysia, Penang.

\section{Authors' Biography}

Toh Seong Chong is an Associate Professor of Centre of Instructional Technology and Multimedia (CITM) in Universiti Sains Malaysia (USM). He obtained his Ph.D. in Educational Technology from USM, Malaysia. His research interests are in the area of $3 \mathrm{D}$ visualization, animations, multimedia authoring, and advanced technologies in education.

Zarina Samsudin is an Associate Professor of CITM in USM. She obtained her Doctor of Education (Ed.D) in Computers in Education from University of Minnesota, U.S.A. Her research interests are in the area of instructional technology, issues and copyright in multimedia, and multimedia project management.
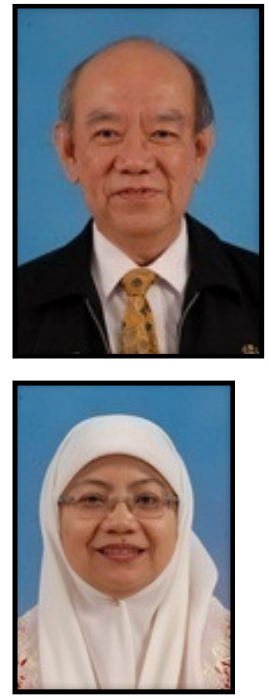
The International Journal of Multimedia \& Its Applications (IJMA) Vol.4, No.5, October 2012

Wan Ahmad Jaafar Wan Yahaya is an Associate Professor of CITM, USM. He holds a Ph.D. degree in Educational Multimedia from the University of Leeds, UK and M.Ed in Computer in Education from the University of Manchester, UK. Currently, he is teaching graduate and undergraduate students in Instructional Multimedia and Persuasive Technology. Dr. Jaafar is a consultant of several projects in the multinational companies as well as many private colleges. He is also involved in the study of ICT initiatives in Malaysian schools as well as in Cambodia. His project entitled "Managing Children Dental Anxiety Through Digital Persuader" won the gold award and special award in the Malaysia Technology Expo (MTE 2012). Another project entitled "Persuasive Multimedia Learning Environment (PMLE)" also won the Gold Award in the 20th International Invention, Innovation, Industrial Design \& Technology Exhibition 2009 (ITEX09) competition. He also won a bronze medal in Seoul International Invention Fair (SIIF) 2010 and in the 23rd 20th International Invention, Innovation, Industrial Design \& Technology Exhibition 2012 (ITEX12) competition. He is currently applying for patent to commercialize the product.

Lili Budiman is a Lecturer at Taylor's University. His research interests are in the area of Search Engine Algorithm, Electronic Commerce, Internet Marketing, Web Content Management System, and Social Media Marketing

Chau Kien Tsong is a Ph.D. candidate at the CITM in USM. His research interests are in the area of multimedia and 3D animation.
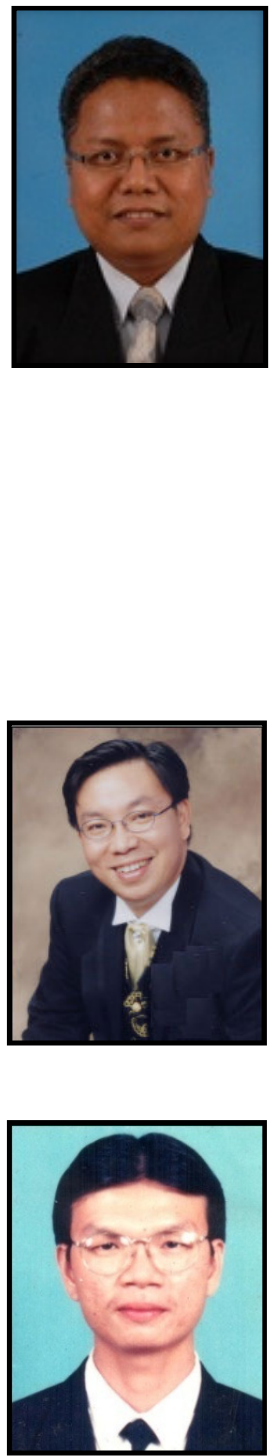